\title{
Challenges of treating hypercapnic respiratory failure with non-invasive ventilation from hospital to home
}

\author{
Gilbert Berdine MD
}

\section{HISTORY OF NIV USE}

Non-Invasive Ventilation (NIV) dates back to the iron lung. ${ }^{1}$ The modern era of NIV arguably began in 1995 with the demonstration of improved outcomes using NIV to treat exacerbation of Chronic Obstructive Pulmonary Disease (COPD). ${ }^{2}$ Subsequently NIV has become standard practice for management of acute exacerbation of COPD to decrease the need for endotracheal intubation and the problems inherent with invasive mechanical ventilation. As a practice becomes standard care, however, there is a danger of extrapolating results to groups beyond those which have been studied. In particular, there are risks of assuming that NIV will be equally effective for other causes of acute respiratory failure, and that NIV will be equally effective for all patients irrespective of the severity of illness.

The use of NIV to treat Obesity Hypoventilation Syndrome (OHS) is more recent and, therefore, is more controversial. ${ }^{3}$ Obesity hypoventilation syndrome is becoming an increasingly common cause of admission to the hospital and intensive care unit. In my experience, many primary providers are using NIV as a fire and forget black box. By black box I mean that something is used as a tool without understanding how it works. By fire and forget I mean that it is assumed that an intervention can be launched and no further course correction is necessary. Both the black box nature and the fire and forget modality can lead to treatment failure resulting in readmission, death, or other significant morbidity. Non-invasive ventilation can fail by different mechanisms at different times, starting with immediate

Corresponding author: Gilbert Berdine

Contact Information: Gilbert.berdine@ttuhsc.edu DOI: 10.12746/swrccc.v7i27.522 failure all the way to failure becoming apparent months later.

\section{IMMEDIATE FAILURE}

In my experience the average expected improvement of arterial $\mathrm{pCO}_{2}$ is about 10 torr. This is consistent with the observations from the landmark report on the use of NIV to treat exacerbations of COPD. ${ }^{2}$ It is rare, in my experience, to see an improvement of arterial $\mathrm{pCO}_{2}$ that exceeds 20 torr. If the condition of the patient is so bad such that an improvement in arterial $\mathrm{pCO}_{2}$ greater than 20 torr would be necessary for success, then NIV should not be considered, and the patient should be intubated. If an improvement in arterial $\mathrm{pCO}_{2}$ of 10 torr is unlikely to be adequate for success, then one should use NIV with caution as therapy, and one certainly should not use NIV in a fire and forget manner. A study on failures of NIV indicated that severity of arterial $\mathrm{pCO}_{2}$ was a very significant predictor of NIV failure. ${ }^{4}$ Other significant predictors of failure were $\mathrm{pH}$, which is determined by arterial $\mathrm{pCO}_{2}$; respiratory rate, which directly determines arterial $\mathrm{pCO}_{2}$; and other parameters (Glasgow Coma Scale and APACHE II score), which arguably are consequences of elevated arterial $\mathrm{pCO}_{2}$.

During the first 24 hours of therapy with NIV, one must determine whether the results are adequate. This requires monitoring of arterial $\mathrm{pCO}_{2}$ while using NIV. It should be kept in mind that these results will be the best that one can expect by continuing NIV. If the results are not adequate, then higher inspiratory pressure or higher backup rate may be necessary. Clinical trials support this concept. ${ }^{5}$ If inadequate results are due to non-compliance with therapy, and compliance does not improve after discussing the situation with the patient and family, then NIV is not going to be successful and other options should be considered. 


\section{SHORT TERM FAILURE (1-3 DAYS)}

These failures occur after the patient has been stabilized on NIV and is transferred from ICU care to a step down unit or general floor. While in the ICU the patient was using NIV 24 hours per day. Outside the ICU, however, the patient frequently uses the NIV at night only. It is very common to see the NIV machine sitting idle in the room. It needs to be clear that the average $\mathrm{CO}_{2}$ level will settle somewhere between the results obtained in the ICU while using NIV 24 hours per day and the respiratory failure results obtained at home with zero use of NIV. Night time may be as little as 4 hours per day. The longer the NIV is used, the closer the average $\mathrm{CO}_{2}$ level will be to the successful result in ICU. The less the NIV is used, the closer the average $\mathrm{CO}_{2}$ level will be to the acute respiratory failure result seen on admission to the hospital. Failure due to inadequate time of NIV use may not be apparent if monitoring is by arterial blood gas taken shortly before NIV is discontinued in the morning.

Outside the ICU, a better measure of average $\mathrm{CO}_{2}$ level will be a venous total $\mathrm{CO}_{2}$. The patient is in two distinct ventilatory states outside of the ICU. While on NIV, the arterial $\mathrm{pCO}_{2}$ will be lower than average, and the patient will be moving $\mathrm{CO}_{2}$ into the atmosphere. While off NIV, the arterial $\mathrm{pCO}_{2}$ will be higher than average, and the patient will be accumulating $\mathrm{CO}_{2}$ due to metabolism. The renal regulation of bicarbonate has a longer time constant than the adjustment of $\mathrm{pCO}_{2}$ by alveolar ventilation and will help average the measure of $\mathrm{CO}_{2}$ between the two extremes. Venous samples are easier to obtain than arterial samples, so venous total $\mathrm{CO}_{2}$ is more suitable to long term monitoring than arterial $\mathrm{pCO}_{2}$-especially in outpatient settings. There needs to be a caveat for patients with separate metabolic acid base disturbances. Patients with end stage renal disease pose extra challenges for monitoring $\mathrm{CO}_{2}$ levels since their acid-base status fluctuates with the dialysis cycle.

Once renal compensation for any acute respiratory failure has completed, if the venous total $\mathrm{CO}_{2}$ level continues to increase each day, the patient will need to increase time of use of the NIV. If the patient is unable or unwilling to comply with increased time of use, NIV will not work long term. If the venous total $\mathrm{CO}_{2}$ reaches a plateau, the risks of longer term failure will increase with higher levels of $\mathrm{CO}_{2}$. In my experience, venous total $\mathrm{CO}_{2}$ greater than $40 \mathrm{mEq} / \mathrm{L}$ should be a red flag, and venous total $\mathrm{CO}_{2}$ less than $30 \mathrm{mEq} / \mathrm{L}$ has a favorable long term prognosis. In agreement with the above concepts, Murphy and Hart suggested that disease severity and the degree to which respiratory failure was successfully treated by NIV were both important determinants to the long term success of home NIV in patients with COPD. ${ }^{5}$ If favorable results are achieved, the patient must be motivated to continue the hours of use forever. There is not going to be anything temporary about the NIV therapy for chronic hypercapnic respiratory failure.

\section{Medium term faIluRe (1-3 weEks)}

These failures tend to be practical failures rather than physiologic failures. These failures are associated with the transition from hospital to home care. If the patient is sent home without NIV equipment, the patient may appear well on discharge, but it will only be a matter of time before the problem repeats itself. There can be problems with the $3^{\text {rd }}$ party payer not agreeing to the same equipment or modality that was successfully used in the hospital. The mask may not fit properly at home. The patient will not have the same degree of supervision at home as in the hospital. There may be nobody available to put the mask back on when it becomes dislodged during sleep. As is seen with compliance with diet, fluid restriction, and other restrictive therapies, the patient may not be as compliant with therapy at home as in the hospital where a nurse will keep reminding patients to use the NIV after interruptions.

The uncertainties and difficulties of transitioning patients with chronic hypercapnic respiratory failure from the hospital to home care are compounded by the uncertainties and difficulties in obtaining insurance approval for home NIV equipment. Standards have been developed for the home treatment of patients with COPD, ${ }^{6}$ but the application of these standards to patients with other problems, such as OHS, are particularly problematic. These difficulties have been made worse by the common use of the term 'BiPAP' in the different contexts of obstructive sleep apnea (OSA) and chronic hypercapnic respiratory failure. Requests for a 'BiPAP' machine to treat hypercapnic 
respiratory failure may be denied without sleep testing. Sleep testing makes no sense for a patient with hypoventilation while awake, but sleep testing may be required to obtain necessary equipment.

\section{LONG TERM FAILURE (1-3 MONTHS)}

These are failures of complacency. Unlike patients who are in pulmonary rehabilitation, there is no improvement over time. The best that can be hoped for is not getting worse over time. There are no goals to motivate continued compliance with therapy. Venous total $\mathrm{CO}_{2}$ levels continue to be the best metric of successful therapy.

\section{VERY LONG TERM FAILURE (LONGER THAN 3 MONTHS)}

These are failures of disease progression. Regardless of whether the underlying disease is COPD, lung restriction, chest wall restriction, or neuromuscular weakness, the respiratory mechanics will deteriorate over time leading to less ability to sustain minute ventilation, worsening respiratory acidosis, and greater renal retention of bicarbonate. I have seen some cases of hypercapnic respiratory failure due solely to OSA gradually resolve over 6 months following successful management of the OSA, but the majority of cases of OHS whom I see involve abnormal respiratory mechanics in addition to sleep apnea.

There is a tendency to attribute every difference among patients to phenotype. Progression of disease within a single patient is not due to phenotype. Differences in disease progression in different patients may be due to phenotype, but it may be an error to categorize early stage disease and late stage disease as two distinct phenotypes.

\section{Conclusions}

NIV has been a successful therapeutic modality for the treatment of acute respiratory failure secondary to COPD in hospitalized patients. This success cannot necessarily be extrapolated to patients with other causes of acute respiratory failure. Nor can this success be necessarily extrapolated to longer terms of therapy outside the hospital. As we accumulate experience in the treatment of chronic hypercapnic respiratory failure with NIV, awareness of both the physiologic and practical causes of treatment failure will be necessary to develop better long term strategies for therapy. As we progress from anecdotal experience to carefully constructed clinical trials, we must group patients together in order to employ statistical methods, but the patients must be grouped on the basis of similarity and separated or stratified on the basis of meaningful differences.

Keywords: Non-invasive ventilation, COPD, obesity-hypoventilation syndrome

From: The Department of Internal Medicine at Texas Tech University Health Sciences Center in Lubbock, Texas

Submitted: $10 / 8 / 2018$

Accepted: 11/14/2018

This work is licensed under a Creative Commons Attribution-ShareAlike 4.0 International License.

\section{REFERENCES}

1. Díaz Lobato S, Mayoralas Alises S. Modern non-invasive mechanical ventilation turns 25. Arch Bronconeumol 2013; 49: 475-479.

2. Brochard L, Mancebo J, Wysocki M, et al. Noninvasive ventilation for acute exacerbations of chronic obstructive pulmonary disease. N Engl J Med 1995;333:817-822.

3. Murphy PB, Janssens J. NIV for OHS without severe OSAS: is it worth it? Thorax 2016 71:877-878.

4. Confalonieri M, Garuti G, Cattaruzza MS, et al. A chart of failure risk for noninvasive ventilation in patients with COPD exacerbation. European Respiratory Journal 2005;25:348-355.

5. Murphy PB, Hart N. Home non-invasive ventilation for COPD: how, who and when? Arch Bronconeumol 2018;54:115-174.

6. Decision Memo for Noninvasive Positive Pressure RADs for COPD (CAG-00052N). https://www.cms.gov/medicarecoverage-database/details/nca-decision-memo.aspx? NCAId $=56 \& v e r=5 \&$ viewAMA $=$ Y \&bc $=$ AAAAAAAAEAAA\& . Accessed 11/12/2018. 